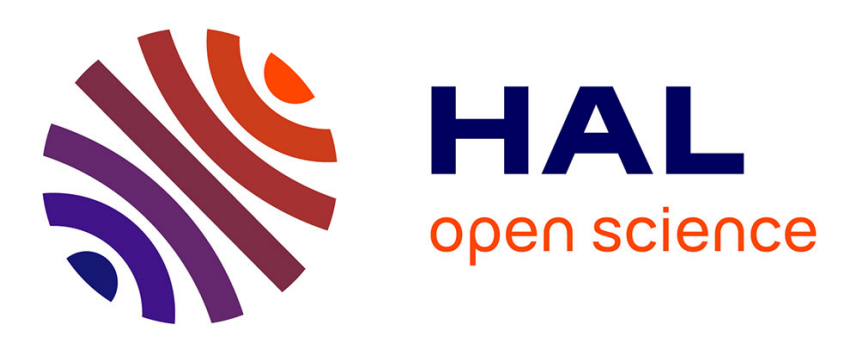

\title{
Quantum dash based directly modulated lasers for long-reach access networks
}

\author{
Siddharth Joshi, Nicolas Chimot, Luiz Anet Neto, Alain Accard, Jean-Guy \\ Provost, Florent Franchin, Abderahim Ramdane, François Lelarge
}

\section{- To cite this version:}

Siddharth Joshi, Nicolas Chimot, Luiz Anet Neto, Alain Accard, Jean-Guy Provost, et al.. Quantum dash based directly modulated lasers for long-reach access networks. Electronics Letters, 2014, 50 (7), pp.534 - 536. 10.1049/el.2013.4121. hal-01081383

\section{HAL Id: hal-01081383 https://hal.science/hal-01081383}

Submitted on 7 Nov 2014

HAL is a multi-disciplinary open access archive for the deposit and dissemination of scientific research documents, whether they are published or not. The documents may come from teaching and research institutions in France or abroad, or from public or private research centers.
L'archive ouverte pluridisciplinaire HAL, est destinée au dépôt et à la diffusion de documents scientifiques de niveau recherche, publiés ou non, émanant des établissements d'enseignement et de recherche français ou étrangers, des laboratoires publics ou privés. 


\section{Quantum Dash based Directly Modulated Lasers for long reach Access Networks}

\author{
S. Joshi, N. Chimot, L. A. Neto, A. Accard, J-G. Provost, F. \\ Franchin, A. Ramdane, and F. Lelarge
}

We demonstrate an innovative $10 \mathrm{Gbps}$ single mode optical transmitter with the capacity of error free transmission in the range of 0 to $100 \mathrm{kms}$ with constant biasing conditions using a Quantum Dash Directly Modulated Laser. We use a commercially available etalon filter as passive optical filter to achieve penalty free transmission with a dynamic extinction ratio (DER) $>6 \mathrm{~dB}$ over a large range of fiber spans.

Introduction: The increase in the performance of digital electronics and desktop computers has resulted in expansion of triple play services in recent years [1]. The interactive internet today, demands gigabit bandwidth provisions. In addition from the service provider point of view, it is desirable to have higher split-ratio for reduction of cost and a longer reach of the network for remotely located subscribers. As the standardization of next generation passive optical access networks (NGPON2) is still under way, it is necessary to develop innovative 10Gbits/s transmitters at $1.55 \mu \mathrm{m}$ for long reach, low cost and high capacity access and metropolitan networks which could be deployed in access networks over the period of next few years. Directly modulated lasers (DMLs) are attractive candidates for access networks owing to their high output power, low threshold current, tolerance to optical feedback, and ability to operate in semi-cooled or un-cooled conditions. However, for a conventional Quantum Well (QW) a DML, the transmission distances are limited to the range of about $30 \mathrm{kms}$, because of frequency chirping at $1.550 \mu \mathrm{m}$ inherent to high bit rate direct modulation. It also proved difficult to achieve high dynamic extinction ratios (DER). Transmissions over $200 \mathrm{kms}$ have readily been demonstrated with DML using different approaches based on proper management of the chirp. These methods use for example a dispersion compensation fibre [2], specific filtering [3-5] reduction of spectral broadening [6] or electronic compensation [7]. However, these solutions require tightly stabilized optical filters, accurate temperature control or specific power consuming electronic detection schemes. We propose here a compact solution for such transmitters using Quantum Dash (Q-Dash) based gain material for optical transmission in the range of 0 to $100 \mathrm{kms}$.

Q-Dash Directly Modulated Lasers: Self-assembled semiconductor quantum-dot (QDot) and quantum-dash (QDash) based lasers appear to be promising devices since higher differential gain and lower chirp are expected. Recently, p-doping of the Qdash active layers led to further improvement of intrinsic dynamic properties [8] and Henry's factors as low as 2.5 have been reported. Un-amplified $10 \mathrm{Gbps}$ transmission in standard single mode fibre from back-to-back up to $65 \mathrm{kms}$ at constant operating conditions was hence demonstrated with an extinction ratio of $8 \mathrm{~dB}$ [9]. In this work, we report that the combination of this promising material system with a commercially available etalon filter enables errorfree uncompensated $10 \mathrm{Gbps}$ transmissions over a record distance of 100 $\mathrm{kms}$ in standard single mode (SMF) fibre span. A constant bias current from back-to-back up to $100 \mathrm{kms}$ with DER greater than $6 \mathrm{~dB}$ are reported. Using DML based on this material, a $-18 \mathrm{~dB}$ onset of coherence collapse was further reported [10], making the demonstration of their compatibility with isolator free operation. These performances pave the way to their widespread use for long reach $(100 \mathrm{kms})$ access networks.

Device Fabrication: For the present study the laser active region is composed of 6 InAs quantum dash layers embedded in $6 \mathrm{~nm}$ thick InGaAsP $\left(\lambda_{\mathrm{g}}=1.45 \mu \mathrm{m}\right)$ Quantum Wells separated by $20 \mathrm{~nm}$-doped InGaAsP $\left(\lambda_{\mathrm{g}}=1.17 \mu \mathrm{m}\right)$ barriers in dash-in-a-well design [8]. The optical confinement is obtained by using a separate confinement heterostructure (SCH) layer, with a thickness of $20 \mathrm{~nm}$ on the p-side and $70 \mathrm{~nm}$ on the nside. For the distributed feedback (DFB) lasers required for transmission evaluation, we have fabricated buried ridge stripe (BRS) laser of lengths $800 \mu \mathrm{m}$ with a $\lambda / 4$ shifted gratings.
Results: The light-current characteristics of the DFB laser at room temperature (fig.1.a), shows a threshold current of about $35 \mathrm{~mA}$, the output power at $100 \mathrm{~mA}$ is about $8 \mathrm{~mW}$ resulting in a $5 \mathrm{dBm}$ power coupled to the fiber. Results on static characteristics on p-doped Qdash lasers can also be found in [11]. As a result of p-doping a higher temperature tolerance for the device is also observed, as can be seen from the alpha-parameter [12] of the device (fig.1.b). In order to evaluate the dynamic properties of the QDash DML, the large signal chirp [13] induced by the modulation of injected current by $1 \mathrm{~ns}$ long square pulses was characterized. In the experiment, the optical signal is analysed through a Mach-Zehnder interferometer, in order to measure the time-resolved amplitude and frequency response. The frequency chirp (fig.2.a) variation at $25^{\circ} \mathrm{C}$ as a function of time when the device is biased for currents between $60 \mathrm{~mA}$ $120 \mathrm{~mA}$ keeping a constant DER of $3 \mathrm{~dB}$ at $10 \mathrm{Gbps}$ in back-to-back (B2B) was evaluated. This corresponds to peak to peak voltage in between $0.6 \mathrm{~V}$ to $2.5 \mathrm{~V}$. For a constant DER the adiabatic chirp increases up to $2.5 \mathrm{GHz}$ and the transient chirp reaches values below $2 \mathrm{GHz}$ (fig. 2.b). This reduced value of transient and adiabatic chirp is valuable for long reach transmission. On the other hand for a constant bias current of $100 \mathrm{~mA}$ with a varying peak to peak voltage we observe an increase in both adiabatic and transient chirp which reaches up to $3 \mathrm{GHz}$ (fig.2(c)). Thus the DER can be increased at the expense of transmission distance. We attribute this strong damping of chirp to both the RC parasitic limitation related to BRS process and to the QDash active layer properties.
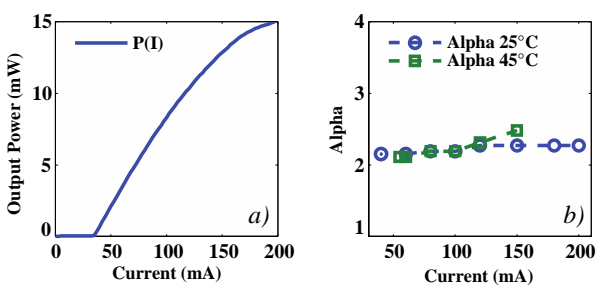

Fig1. Static characteristics of p-doped QDash laser

a L(I) characteristics of the DFB laser under evaluation at room temperature $b$ Measured $\alpha$-parameter constant over large range of current both at room temperature and in semicooled operation
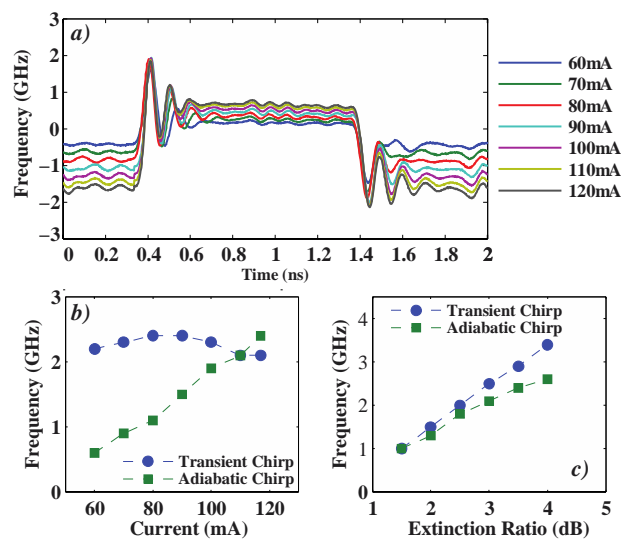

Fig.2: Large signal chirp of a p-doped QDash laser

a Time resolved instantaneous frequency variation with varying biasing current ranging from 60 to $120 \mathrm{~mA}$ and peak-to-peak current is adjusted for constant extinction ratio of $3 \mathrm{~dB}$

b Measured chirp against extinction ratio at constant bias current of $100 \mathrm{~mA}$

c Measured chirp against bias current at constant DER of $3 \mathrm{~dB}$

A standard $10 \mathrm{Gbps}$ nonreturn-to-zero (NRZ) laser modulation is realized with a pseudorandom binary sequence (PRBS) generator emitting $2^{31}-1$ long words. Power launched into the fibre is maintained to $+3 \mathrm{dBm}$ in order to minimize the non-linear effects. The transmitted NRZ signal is sent to an APD receiver before error detection. Fig.3a shows the bit error rate (BER) measured at $25^{\circ} \mathrm{C}$. Biasing current and peak-to-peak modulation current are chosen to optimize the transmission after $100 \mathrm{kms}$ in SMF and these conditions are kept constant for other transmission distances. Floor free transmission at $10 \mathrm{Gbps}$ up to a bit-error rate of 1E10 is achieved over $100 \mathrm{kms}$ of SMF. DER is $2.8 \mathrm{~dB}$ (fig. $3 \mathrm{~b}-\mathrm{d}$ ). It can be noticed that the BER curve for $25 \mathrm{kms}$ has a larger penalty compared to the other distances. This can be related to the interaction of the laser chirp with fiber dispersion as discussed in [5, 14]. Thus, the QDash based 
DMLs have the potential to transmit over distances as long as $100 \mathrm{kms}$, without resorting to any external control. However, the ER remains not compatible with access standards ( 2.7 instead of $6 \mathrm{~dB}$ ).

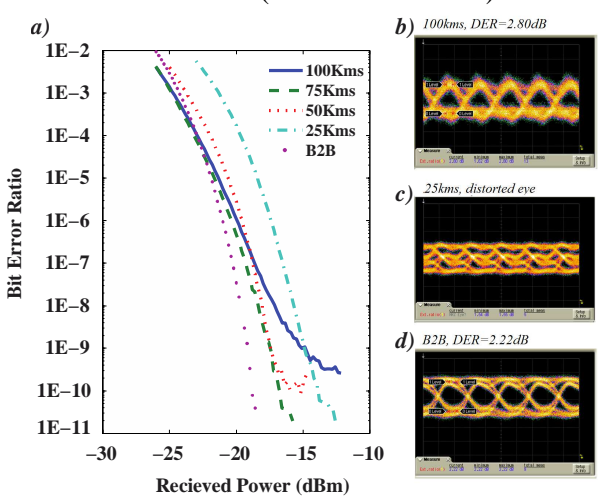

Fig3 Optical transmission without an Etalon filter

a BER without using the etalon filter

b-d Corresponding eye diagram after $100 \mathrm{~km}$ transmission at $25 \mathrm{kms}$ and in $\mathrm{B} 2 \mathrm{~B}$

These measurements were subsequently repeated with a conventional etalon filter added before the fiber span. The steepness of the etalon is around $1 \mathrm{~dB} / \mathrm{GHz}$, which is consistent with the adiabatic chirp of the laser. The low steepness value of the filter make the amplitude reshaping robust to any variations. The filter conditions are set and fixed for the entire range of distances measured, i.e no adjustment to the filter is required for distance from B2B all the way to $100 \mathrm{kms}$. ER after the etalon filter is found to be greater than $6 \mathrm{~dB}$ as shown in fig. 4(b). One can note that the introduction of filter in the optical channel resulted in the Bit-error-ratio curves to be almost penalty free (fig. 4).

The Quantum Dash based transmitters combined with a commercial etalon filter hence prove to be very adapted for long reach access networks. The advantage of this approach is that the filter conditions are not changed over the entire range of distances, thus yielding very high flexibility. Also, this method requires no feedback loop. These transmitters can also be used to achieve a high split ratio, and thus reducing cost of the access network infrastructure.

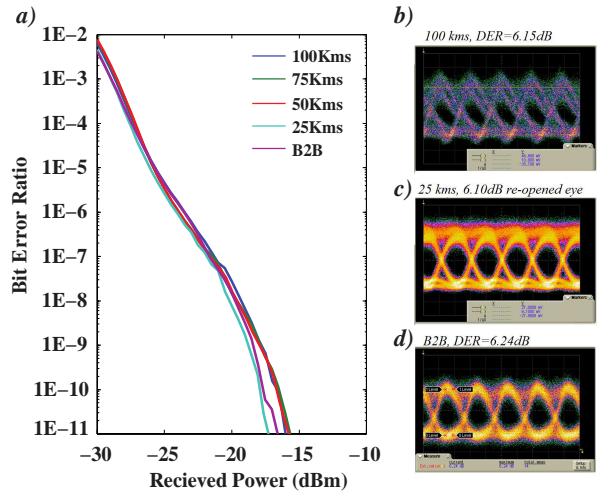

Fig4: Optical transmission using on Etalon filter a BER with etalon filter

b-d Corresponding eye diagram after $100 \mathrm{~km}$ transmission at $25 \mathrm{kms}$ and in $\mathrm{B} 2 \mathrm{~B}$

Conclusion: In this work we demonstrate compact, low consumption, long-reach optical transmitters for NGPON2 using Q-Dash DML. Error free transmission in the range of 0 to $100 \mathrm{kms}$ at constant biasing conditions was demonstrated. These results reinforce the high potential of p-doped Qdash active layers for high bit rate modulation and open the way to truly low-cost DML for access and metropolitan applications. In addition using an etalon filter with the QDash-DML leads to a high extinction ratio with high tolderence to the filter conditions. We believe that this approach has the potential to provide optical sources for NGPON2, which require a high optical budget, longer reach to remote ONUs with high flexibility.
Acknowledgments: The authors would like to acknowledge the support of EU FP7 ITN PROPHET, grant no. 264687 and the Agence Nationale de la Recherche, France for the DIQDOT project.

(C) The Institution of Engineering and Technology 2014

20 December 2013 doi: 10.1049/el.2013.4121

One or more of the Figures in this Letter are available in colour online. S. Joshi, N. Chimot, A. Accard, J.-G. Provost, F. Franchin and F. Lelarge (III-V Lab, A Joint Laboratory of 'Alcatel Lucent Bell Labs', 'Thales Research \& Technology' and CEA-LETI, Route de Nozay, 91460 Marcoussis, France)

E-mail: siddharth.joshi@3-5lab.fr

L.A. Neto (Enssat, 6, rue de Kerampont, 22305 Lannion, France) Q4 A. Ramdane (LPN-CNRS, Route de Nozay, 91460 Marcoussis, France)

\section{References}

1 Kazovsky, L., Shaw, W., Gutierrez, D., Cheng, N., and Wong, S.: 'Nextgeneration optical access networks', J. Lightwave Technol., 2007, 25, pp. 3428-3442

2 Mizuhara, O., Nguyen, T.V., Tzeng, L.D., and Yeates, P.D.: '10 Gbits/s transmission experiment using direct modulation and including 8:1 time division-multiplex setup', Electron. Lett., 1995, 31, pp. 660-662

3 Morton, P.A., Tanbun-Ek, T., Logan, A., Ackerman, D.A., Shtengel,

G., Chand, J.E., Johnson, R.D., Yadvish, R.D., Sergent, M., and Sciortino, P.F.: 'High speed, low chirp, directly modulated $1.55 \mu \mathrm{m}$

DFB laser sources for $10 \mathrm{Gbit} / \mathrm{s}$ local distribution'. Proc. Optical Fiber Communication, 1996, TuH6, pp. 39-40

4 Matsui, Y., Mahgerefteh, D., Zheng, X., Liao, C., Zhencan, F.F., McCallion, K., and Tayebati, P.: 'Chirp-managed directly modulated laser (CML)', IEEE Photonics Technol. Lett., 2006, 18, pp. 385-387

5 Wedding, B.: 'New method for optical transmission beyond dispersion limit', Electron. Lett., 1992, 28, pp. 1298-1300

6 Binder, J., and Kohn, U.: '10 Gbit/s-dispersion optimized transmission at $1.55 \mu \mathrm{m}$ wavelength on standard single mode fiber', IEEE Photonics Technol. Lett., 1994, 6, pp. 558-560

7 Feuer, M.D., Huang, S.Y., Woodward, S.L., Coskun, O., and Boroditsky, M.: 'Electronic dispersion compensation for a $10 \mathrm{~Gb} / \mathrm{s}$ link using a directly modulated laser', IEEE Photonics Technol. Lett., 2003, 15, pp. $1788-1790$

8 Lelarge, F., Brenot, R., Rousseau, B., Martin, F., Poingt, F., Legouezigou, L., Pommereau, F., Accard, A., Make, D., Chimot, N., and Van Dijk, F.: 'Effect of p-doping on temperature and dynamic performances of $1550 \mathrm{~nm} \mathrm{InAs} / \mathrm{InP}$ quantum dash based lasers'. IEEE Int. Conf. Indium Phosphide \& Related Materials', 2009, ThB1.6, pp. 383386

9 Chimot, N., Joshi, S., Lelarge, F., Accard, A., Provost, J.-G., Franchin, F., and Debregeas-Sillard, H.: 'QDash-based directly modulated lasers for next-generation access network, photonics technology letters', IEEE, 2013, 25, (17), pp. 1660-1663

10 Zou, Q., Merghem, K., Azouigui, S., Martinez, A., Accard, A., Chimot, N., Lelarge, F., and Ramdane, A.: 'Feedback-resistant p-type doped InAs/InP quantum-dash distributed feedback lasers for isolator-free 10 $\mathrm{Gb} / \mathrm{s}$ transmission at $1.55 \mu \mathrm{m}$ ', Appl. Phys. Lett., 2010, 97, pp. $231115-$ 231118

11 Chimot, N., Joshi, S., Aubin, G., Merghem, K., Barbet, S., Accard, A., Ramdane, A., and Lelarge, F.: ' $1550 \mathrm{~nm}$ InAs/InP quantum dash based directly modulated lasers for next generation passive optical network'. Indium Phosphide and Related Materials (IPRM), 2012, 27-30 August 2012, vol., no., pp. $177-180$

12 Provost, J.G., and Grillot, F.: 'Measuring the 'chirp and the linewidth enhancement factor of optoelectronic devices with a Mach-Zehnder interferometer', IEEE Photonics J., 2011, 3, (3), pp. 476-488

13 Saunders, R.A., King, J.P., and Hardcastle, I.: 'Wideband chirp measurement technique for high bit rate sources', Electron. Lett., 1994, 30, (16), pp. 1336-1338

14 Mohrdiek, S., Burkhard, H., Steinhagen, F., Hillmer, H., Losch, R., Schlapp, W., and Gobel, R.: '10-Gb/s standard fiber transmission using directly modulated $1.55-\mu \mathrm{m}$ quantum-well DFB lasers', IEEE Photonics Technol. Lett., 1995, 7, (1), pp. 1357-1359 